\title{
ETAPAS PARA A ELABORAÇÃO DE UM GUIA PRÁTICO DE PROCEDIMENTOS DE COLETA E PREPARO DE AMOSTRAS PARA A DETECÇÃO DE PATÓGENOS VIRAIS EM CAMARÕES PENEÍDEOS
}

Originais recebidos em: 07/11/2011

Aceito para publicação em: 18/01/2012

Camilla Adriano Wojcikiewicz

Universidade Federal de Santa Catarina camillablw@hotmail.com

Marcos Vinicius Pfleger Rosa

Universidade Federal de Santa Catarina marcospfleger@gmail.com

Maria Risoleta Freire Marques

Universidade Federal de Santa Catarina risomar@mbox1.ufsc.br

Erro! Fonte de referência não encontrada.

Tendo em vista o considerável crescimento da carcinicultura no Brasil, e com ele a ocorrência de enfermidades, acompanhadas de perdas econômicas significativas no setor, os alunos do projeto de extensão do Laboratório de Biomarcadores de Contaminação Aquática e Imunoquímica (LABCAI), o qual integra $\mathrm{o}$ Núcleo de Estudos em Patologia Aquícola (NEPAq), reuniram informações sobre o diagnóstico de enfermidades virais em camarões peneídeos, realizado no laboratório, bem como sobre os métodos de coleta e preparo de amostras para essas análises laboratoriais, visando a elaboração de um guia prático de procedimentos. Esse guia prático visa orientar o produtor, o agente em sanidade, o extensionista e as demais pessoas interessadas sobre as etapas que ocorrem desde a coleta dos animais nas fazendas até o diagnóstico laboratorial final. A elaboração do guia foi efetuada com base nos parâmetros e procedimentos de diagnósticos rotineiramente utilizados pelo LABCAI e na avaliação da qualidade de amostras coletadas nos cultivos e em laboratórios de produção de pós-larvas. A primeira versão do guia foi submetida a uma avaliação preliminar, através de um questionário estruturado, cujo resultado forneceu subsídios para a elaboração da versão final. Uma vez concluída, essa segunda versão será submetida a uma nova avaliação pelo público-alvo e, em seguida, o guia será utilizado como material educativo e de orientação e divulgação.

Palavras-chave: Carcinicultura. Camarões. Diagnóstico. Guia-prático.

STEPS TO ELABORATE AN INFORMATIVE
FOLDER ABOUT SAMPLING AND
PREPARING SAMPLES FOR THE DETECTION
OF VIRAL PATHOGENS IN PENAEID SHRIMP

\begin{abstract}
Due to the significant growth of shrimp farming in Brazil, the emergence of diseases has come along, followed by the consequent economic losses. Therefore, the students participating in the extension project carried out at the Laboratory of Biomarkers of Aquatic Contamination and Immunochemistry (LABCAI), gathered information about procedures for the diagnosis of shrimp viral diseases performed in the laboratory, as well as about methods of sampling and preparation of samples, in order to elaborate a guide of practical procedures. This guide aims to warn producers, sanitary technician, field workers and general public about the different steps that take place from sampling in the farm to the final laboratory diagnosis. This guide was based on the diagnostic procedures routinely used in the LABCAI and also in the quality of the samples from shrimp farms and laboratories of post-larvae production. The first version of the guide has been submitted to a preliminary evaluation using previously structured set of questions. The results will contribute to prepare a final version of the guide. The second version of the guide will be submitted to a new public evaluation and will later be used as an informative and educative material.
\end{abstract}

Keywords: Shrimp Farming. Shrimp. Diagnosis. Practical guide. 
Etapas para a Elaboração de um Guia Prático de Procedimentos de Coleta e Preparo de Amostras para a Detecção de Patógenos Virais em Camarões Peneídeos

\section{INTRODUÇÃO}

Atualmente, a carcinicultura mundial está distribuída em mais de quarenta países da Ásia e Américas do Norte, Central e do Sul, tendo registrado um crescimento significativo nas últimas duas décadas.

Em Santa Catarina, a produção de camarões, impulsionada com a introdução da espécie Litopenaeus vannamei no estado no ano de 1998, apresentou um rápido crescimento entre 2001 e 2004, mostrando um incremento significativo no número de fazendas, na área de cultivo e na produção. De 564 toneladas registradas em 2001, a produção atingiu 4.189 toneladas em 2004, distribuídas em 106 fazendas e 1.563 hectares de viveiros (COSTA, 2010). Entretanto, nos anos subsequentes, essa situação foi drasticamente alterada, em função do registro do vírus da síndrome da mancha branca (White Spot Syndrome Virus, WSSV), nos cultivos do Sul do estado no final de 2004 (SEIFFERT et al., 2005; MOSER et al., 2010). Em 2009, o setor registrou uma produção de apenas 172 toneladas, em uma área de 190 hectares de viveiros, distribuídos em 19 fazendas operantes (COSTA, 2010).

De acordo com Marques et al. (2006), a mortalidade maciça de camarões gera prejuízos econômicos incalculáveis, sendo as enfermidades de etiologia viral aquelas consideradas como a maior limitação ao sucesso dos cultivos em nível mundial.

Diante da diversidade de patógenos virais que podem estar potencialmente presentes nos cultivos de camarões, os quais tem se tornado cada vez mais intensivos, o Laboratório de Biomarcadores de Contaminação Aquática e Imunoquímica (LABCAI) do Departamento de Bioquímica do Centro de Ciências Biológicas, laboratório que integra o Núcleo de Estudos em Patologia Aquícola (NEPAq), buscou compartilhar com os produtores, veterinários, engenheiros de aquicultura, agentes em sanidade, extensionistas e com o público interessado em carcinicultura, uma visão geral sobre as análises laboratoriais e o diagnóstico de enfermidades de etiologia viral em amostras provenientes de cultivos de camarões e de laboratórios de produção de pós-larvas. A essa visão geral, buscou-se adicionar orientações sobre a forma correta de coleta e preparação das referidas amostras, bem como informações sucintas sobre os principais vírus encontrados nos cultivos.

A criação de um folder ou guia prático de procedimentos, sucinto e claro, foi a maneira mais direta de reunir essas informações e facilitar a efetuar a colaboração e a troca de informações entre o laboratório e os setores produtivo e de controle sanitário, visando facilitar o entendimento sobre a importância do monitoramento constante e do diagnóstico precoce dos cultivos, bem como da certificação sanitária de reprodutores e de pós-larvas. 
Etapas para a Elaboração de um Guia Prático de Procedimentos de Coleta e Preparo de Amostras para a Detecção de Patógenos Virais em Camarões Peneídeos

Durante o período de oito meses (01/06/2010 a 01/02/2011), os alunos do projeto de extensão Monitoramento e Diagnóstico de Enfermidades de Etiologia Viral em Camarões Peneídeos analisaram e utilizaram os protocolos desenvolvidos e implantados no laboratório, praticando antecipadamente os procedimentos referentes ao diagnóstico de enfermidades em camarões peneídeos, de forma a transpor mais facilmente as etapas do trabalho realizado no laboratório, a partir do recebimento das amostras, provenientes das fazendas de cultivo e dos laboratórios de produção, até o momento final do diagnóstico. Paralelamente, foram também analisados os aspectos gerais relacionados com a qualidade das amostras recebidas.

Após o período de treinamento e conhecimento das técnicas e dos procedimentos de diagnóstico, foi possível iniciar a elaboração do folder educativo, voltado ao produtor de camarões e/ou ao técnico coletor e que pudesse ainda atingir o público em geral.

\section{MATERIAL E MÉTODOS}

A metodologia foi constituída, inicialmente, da análise dos protocolos de procedimentos desenvolvidos e em utilização no LABCAI, os quais abrangem desde a coleta das amostras até a conclusão do diagnóstico. Foram selecionados os protocolos utilizados e aplicados na detecção dos seguintes vírus: vírus da síndrome da mancha branca (White Spot Syndrome Virus, WSSV), vírus da necrose hipodermal e hematopoiética infecciosa (Infectious Hypodermal and Haematopoietic Necrosis Virus, IHHNV) e vírus da mionecrose infecciosa (Infectious Mionecrosis Virus, IMNV), os quais foram registrados no país e estão entre aqueles de notificação obrigatória, de acordo com a OIE (WORLD ORGANIZATION FOR ANIMAL HEALTH, 2010), da qual o Brasil é signatário.

Finda essa etapa, os graduandos de Engenharia de Aquicultura envolvidos neste projeto realizaram todos os protocolos experimentais analisados, do início até o resultado final. Para tal, foram utilizadas amostras já recebidas e analisadas anteriormente no laboratório. Contando com o apoio e a troca de experiências com alunos de pós-graduação da equipe do LABCAI, os acadêmicos realizaram as seguintes atividades experimentais, de acordo com os protocolos desenvolvidos anteriormente no referido laboratório (MACIEL; MARQUES, 2003; MOSER, 2005; SOUZA, 2008):

- PCR (Reação em Cadeia da Polimerase): técnica altamente sensível de amplificação de DNA. Através de uma reação enzimática in vitro, utilizando 
Etapas para a Elaboração de um Guia Prático de Procedimentos de Coleta e Preparo de Amostras para a Detecção de Patógenos Virais em Camarões Peneídeos

um DNA polimerase, são obtidas cópias múltiplas de uma sequência alvo de DNA desejada.

- Eletroforese: Permite a visualização dos resultados da reação de PCR, através da separação em um campo elétrico dos fragmentos de DNA amplificados, os quais são caracterizados através do seu tamanho (número de pares de base).

- Hibridização in Situ: técnica baseada na detecção de pequenos segmentos (sequencias alvo) de DNA ou RNA, a partir de sua hibridização com sondas específicas (sequência de nucleotídeos complementares à sequência alvo do próprio vírus).

Além dessas atividades, consideradas como as estratégias principais na detecção de enfermidades virais, os discentes ainda obtiveram treinamento em atividades vinculadas a etapas anteriores a esses procedimentos, relacionados à preparação das amostras para as análises moleculares, como homogeneização de tecido animal para extração de DNA e RNA.

Os procedimentos foram complementados através da avaliação conjunta dos resultados obtidos e da qualidade das amostras utilizadas. Paralelamente, foi realizada também uma revisão bibliográfica sobre os vírus selecionados para o diagnóstico, as doenças virais comuns aos camarões peneídeos no Brasil e no mundo, e os procedimentos laboratoriais utilizados.

Com base nesse trabalho, deu-se início à compilação das informações para a elaboração de um folder de divulgação, orientação e conscientização do público-alvo.

Como instrumento de avaliação do folder elaborado, foi preparado e aplicado um questionário estruturado para avaliar o seu formato, o seu grau informativo, a sua clareza, a sua abrangência e seu grau de segmentação em relação ao público-alvo, amostrando-se, nessa etapa inicial, um universo restrito, constituído de dez pessoas entre os membros do próprio LABCAI e alunos de graduação em Engenharia de Aquicultura.

\section{RESULTADOS E DISCUSSÃO}

Ao término das atividades propostas, a primeira etapa de elaboração do folder e avaliação preliminar foi concluída. O folder foi apresentado a alunos de graduação de Engenharia de Aquicultura e a profissionais e acadêmicos do LABCAI, vinculado a um questionário estruturado para sua avaliação, o qual foi respondido anonimamente on-line. 

para a Detecção de Patógenos Virais em Camarões Peneídeos

Alterações significativas foram sugeridas, visando uma melhor compreensão do assunto e dos procedimentos por parte do público em geral. As respostas obtidas estão mostradas nos gráficos apresentados a seguir, nos quais as respostas foram compiladas em níveis distintos de avaliação (entre ótimo e ruim).

Os resultados foram explorados visando traçar as diretrizes gerais para as alterações a serem efetuadas nessa primeira versão do material preparado, com o objetivo de melhorar sua apresentação geral e para maior clareza dos procedimentos de coleta, tendo em vista o público em geral.

Gráfico 1: Questões para a avaliação da qualidade do folder (ideia geral e formato de apresentação)
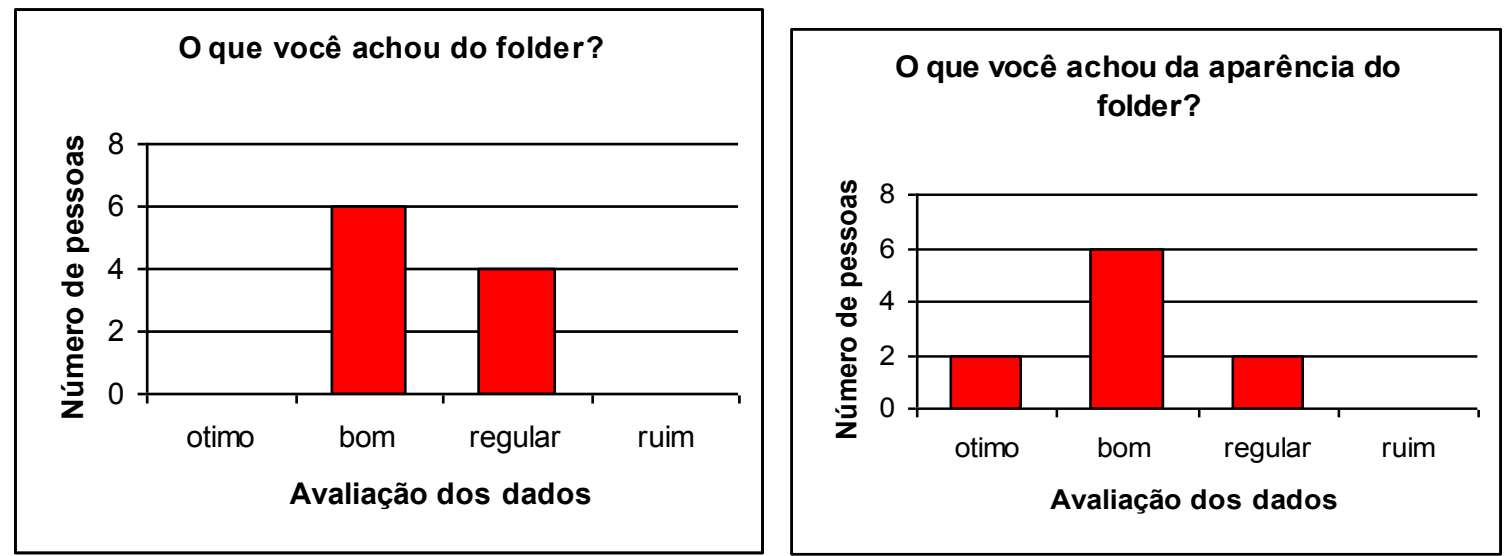

FONTE: Dados compilados pelos autores a partir das respostas ao questionário estruturado.

Com base na avaliação da qualidade do folder (Gráfico 1), os resultados do questionário estruturado indicaram que a apresentação geral deve ainda ser trabalhada, uma vez que $40 \%$ dos indivíduos classificaram-na dentro do nível "regular" de qualidade. Em particular, a melhoria da qualidade das figuras (como, por exemplo, em relação a gama de cores destas) foi mencionada em $20 \%$ das respostas. No entanto, deve ser ressaltado que, para essa versão do folder, foi realizada uma impressão simples e econômica, utilizando uma impressora jato de tinta comum, o que pode ter contribuído para os resultados registrados.

Gráfico 2: Níveis adequados de informação e formatação dos dados 
Etapas para a Elaboração de um Guia Prático de Procedimentos de Coleta e Preparo de Amostras para a Detecção de Patógenos Virais em Camarões Peneídeos
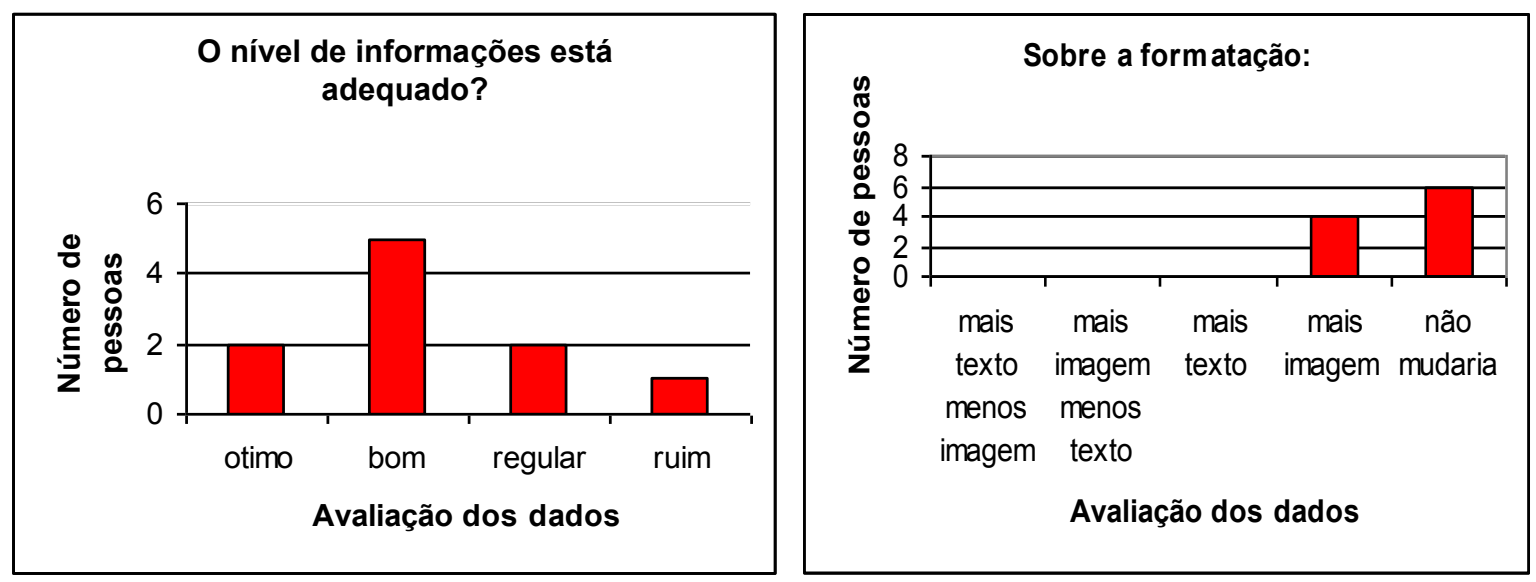

FONTE: Dados compilados pelos autores a partir das respostas ao questionário estruturado.

Por outro lado, os resultados do questionário estruturado compilados no Gráfico 2 indicaram que o nível do conteúdo informativo do folder pode ser considerado adequado, uma vez que $70 \%$ dos indivíduos classificaram-no dentro das categorias de nível "ótimo" e "bom". Ainda em consonância com os resultados apresentados anteriormente no Gráfico 1, $40 \%$ dos avaliadores sugeriram a inclusão de um maior número de figuras e/ou ilustrações (Gráfico 2).

Gráfico 3: Procedimentos em práticas laboratoriais e informações sobre as doenças
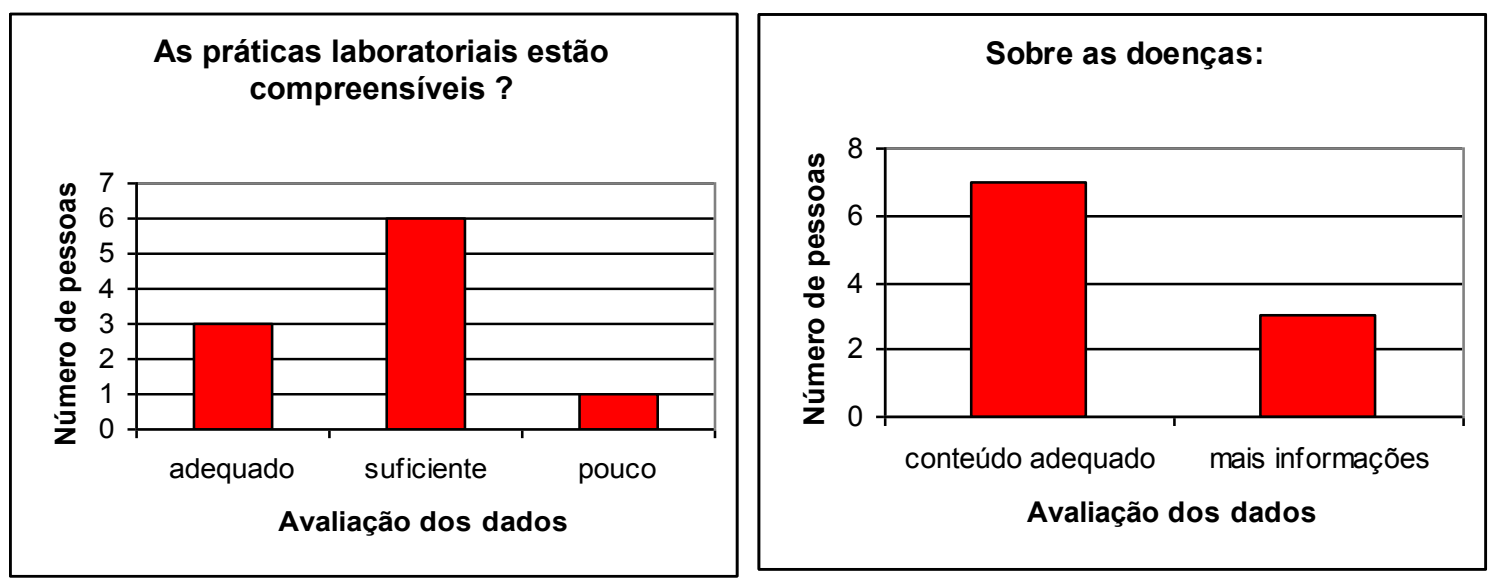

FONTE: Dados compilados pelos autores a partir das respostas ao questionário estruturado.

Em relação à avaliação das informações relativas às práticas laboratoriais utilizadas (Gráfico 3), podemos considerar que o material atendeu aos objetivos propostos, uma vez que foi considerado adequado em $30 \%$ das respostas e suficiente em $60 \%$ delas. Da mesma forma, o objetivo relativo ao conteúdo informativo geral sobre as doenças de etiologia viral incluídas 
Etapas para a Elaboração de um Guia Prático de Procedimentos de Coleta e Preparo de Amostras para a Detecção de Patógenos Virais em Camarões Peneídeos

no escopo dos diagnósticos em foco no folder (WSSV; IHHNV e IMNV) pode ser considerado como contemplado, uma vez que $70 \%$ das respostas consideraram-no adequado.

Gráfico 4: Público-alvo e satisfação sobre a aplicabilidade do folder
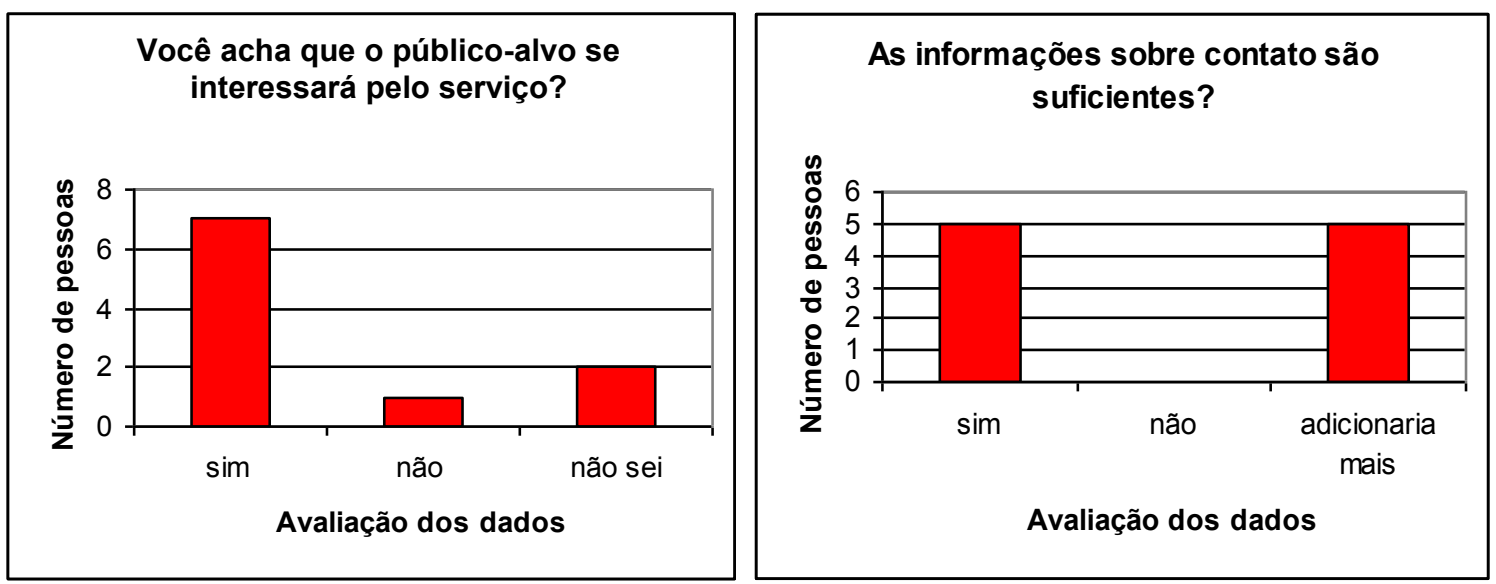

FONTE: Dados compilados pelos autores a partir das respostas ao questionário estruturado.

Em relação à avaliação do provável interesse por parte do público-alvo pelas análises laboratoriais realizadas e pelas informações relacionadas ao tema de enfermidades virais em carcinicultura, conforme apresentado no folder, as respostas obtidas são favoráveis a uma contribuição efetiva do material junto à comunidade de usuários potenciais (Gráfico 4). Por outro lado, a questão das informações sobre as formas de contato com o LABCAI e/ou acesso aos serviços apresentaram-se limitadas e devem ser revistas e melhor elaboradas na próxima versão (versão revisada) do folder (Gráfico 4).

Com base nos resultados obtidos, além das incorporações das sugestões apresentadas, os autores pretendem ainda ampliar o escopo do material elaborado, através da preparação desse material em um formato a ser veiculado on-line, no site do LABCAI.

De forma geral, mesmo havendo indicações concretas no sentido de realizar revisões em aspectos e pontos específicos do folder ora elaborado, os dados indicam uma avaliação positiva da iniciativa e do material preliminar elaborado, por parte dos graduandos do curso de Engenharia de Aquicultura que responderam ao questionário e dos profissionais e demais acadêmicos do LABCAI. Esperamos obter o resultado semelhante por parte dos produtores e técnicos atuantes no setor, sendo este o direcionamento da segunda etapa deste projeto de extensão: realizar as modificações sugeridas nessa primeira versão do folder e apresentá-lo ao público-alvo, submetendo-o à sua avaliação e registrando a sua receptividade. Com base nessa nova etapa, passar então a realizar a sua distribuição e acompanhar a sua utilização.

Extensio: R. Eletr. de Extensão, ISSN 1807-0221 Florianópolis, Ano 8, n. 12, p. 100-108, 2011. 106 

para a Deteç̧ão de Patógenos Virais em Camarões Peneídeos

Após todo esse processo, o folder, na sua versão revisada, estará pronto, podendo circular e ser utilizado entre produtores, técnicos em extensão, agentes em sanidade animal, veterinários e demais pessoas envolvidas na carcinicultura, em particular junto a Companhia Integrada de Desenvolvimento Agrícola de Santa Catarina (CIDASC) e Empresa de Pesquisa Agropecuária e Extensão Rural de Santa Catarina (EPAGRI), entidades com as quais o LABCAI já vem colaborando de forma sistemática desde 2005.

Ainda como parte deste projeto de extensão, pretendemos atingir também públicos distintos dos até aqui considerados como alvo, incluindo associações de produtores ou carcinicultores, além de um maior número de graduandos de Engenharia de Aquicultura e de outros cursos de graduação relacionados com a área, nesta e em outras Universidades, além de empresas privadas e outros órgãos públicos governamentais, como o Ministério de Agricultura Pecuária e Abastecimento (MAPA), com o qual o LABCAI vem também desenvolvendo trabalho em colaboração desde 2005.

\section{CONSIDERAÇÕES FINAIS}

Visando integrar os diversos setores da carcinicultura, contribuir com o monitoramento sanitário dos cultivos e minimizar o impacto das enfermidades virais sobre a produção, o projeto de extensão Monitoramento e Diagnóstico de Enfermidades de Etiologia Viral em Camarões Peneídeos buscou apresentar à comunidade informações sobre os aspectos básicos das enfermidades virais registradas nos cultivos brasileiros e sobre a importância da coleta correta, preservação e qualidade das amostras a serem submetidas a exames laboratoriais para a detecção de patógenos de etiologia viral, com base nos procedimentos e técnicas realizadas no LABCAI desde 2005. Dessa forma, teve-se o intuito de divulgar e promover o conhecimento sobre a base de apoio para a carcinicultura, formada entre pesquisa, produção, extensão e sanidade, já existente em Santa Catarina, a qual pode ser ainda melhor aproveitada e contribuir de forma mais efetiva para o setor, tanto em nível estadual, como em nível nacional, além de promover a educação e a conscientização do público em geral, tanto aquele relacionado direta ou indiretamente com as atividades de cultivo de camarões peneídeos, como o consumidor final. 
Etapas para a Elaboração de um Guia Prático de Procedimentos de Coleta e Preparo de Amostras para a Detecção de Patógenos Virais em Camarões Peneídeos

\section{REFERÊNCIAS}

COSTA, Sérgio Winckler. Aquicultura no estado de Santa Catarina: situação atual e perspectivas.

Revista da ABCC, v.12, p.49-50, 2010.

MACIEL, Maria Luiza Toschi; MARQUES, Maria Risoleta Freire. Avaliação da ocorrência do vírus da síndrome da mancha branca (White Spot Syndrome Virus - WSSV) em cultivos do camarão marinho (Litopenaeus vannamei) através da Reação em Cadeia de Polimerase: investigação preliminar. In: Congreso Internacional Virtual de Acuicultura, 2003, p. 231-236. Disponível em: $<$ www.civa2003.org $>$. Acesso em 07 dez. 2010.

MARQUES, Maria Risoleta Freire; MOSER, Juliana Righetto; MULLER, Isabel Cristina. Virologia de crustáceos e métodos moleculares de diagnóstico. In: SILVA-SOUZA, Ângela Teresa (Org.). Sanidade de Organismos Aquáticos. Maringá: ABRAPOA, 2006.

MOSER, Juliana Righetto. Respostas bioquímicas do camarão-branco, Litopenaeus vannamei, exposto a carbofuran e determinação da prevalência natural do vírus da Necrose Hipodermal e Hematopoiética Infecciosa. Dissertação (Mestrado em Biotecnologia), UFSC, 2005.

MOSER, Juliana Righetto; FRAGA, Ana Paula Medeiros; SOUZA, Talita Medeiros; GOMES, Rafaela Pino; CORDEIRO, Tatiana Milani; MARQUES, Maria Risoleta Freire. Monitoramento do vírus da síndrome da mancha branca no estado de Santa Catarina durante cinco anos (de 2005 a 2010). In: XI Encontro Brasileiro de Patologistas de Organismos Aquáticos. 19 a 22 de julho de 2010.

SEIFFERT, Walter; COSTA, Sérgio Winckler; MAGGIONI, Daniela Gonçalves. A mancha branca em Santa Catarina. Revista Panorama da Aquicultura, v.15, p.51-53.

SOUZA, Talita Medeiros. Detecção do WSV em Litopenaeus vannamei por métodos moleculares de diagnostico: Hibridização in situ e PCR em tempo real. Dissertação (Mestrado em Aquicultura), UFSC, 2008.

OIE - WORLD ORGANIZATION FOR ANIMAL HEALTH. Aquatic Animal Health Code, 2010. Disponível em: $<$ http://www.oie.int/en/international-standard-setting/aquatic-code/access-online/>. Acesso em 07 dez. 2010. 